\title{
Modos de Viver Pulsáteis: Navegando nas Comunidades Trans sobre Hormônios
}

Pulsatiles ways of Life: Navigating the Trans Communities about Hormones Modos de vivir pulsátiles: Navegando por las Comunidades Trans acerca de las Hormonas

\section{Dolores Galindo}

Universidade Federal de Mato Grosso (UFMT), Cuiabá, Mato Grosso, Brasil.

\section{Ricardo Pimentel Méllo}

Universidade Federal do Ceará (UFC), Fortaleza, Ceará, Brasil.

\section{Renata Vilela}

Universidade Federal de Mato Grosso, Mato Grosso, Brasil.

\section{Resumo}

Este trabalho estuda mensagens trocadas em fóruns de discussões virtuais que têm como foco os usos trans de hormônios, isto é, a hormonização, termo cunhado para diferenciá-los da hormonoterapia, administrada por profissionais de saúde. Foram pesquisadas três comunidades alojadas na rede social Orkut, contabilizando um total de 370 fóruns, sendo analisados os usos de hormônios e os relatos de desencontros entre usuárias e profissionais de saúde. Observa-se que se de um lado a hormonização aumenta os efeitos adversos decorrentes de intervenções baseadas em elevadas dosagens de fármacos, de outro, configura-se como uma resistência diante de dispositivos clínico-patologizantes.

Palavras-chave: Modos de viver; Comunidades trans; Hormônios.

\begin{abstract}
This paper aims at studying exchanged messages in discussion forums in the social network, focused on the Trans' uses of composition of hormonal regimens. As a method were surveyed 3 (three) communities that have intense exchange of messages about hormonal regimens, with a total of 370 boards, and analyzed the modes of administration of hormones and reports of meetings with professionals. In the messages exchanged was observed an increase of doses and combinations compared to formal protocols, which increases the adverse effects of these interventions and configure resistances against clinical-pathological dispositive.
\end{abstract}

Keywords: Ways of life; Trans communities; Hormones. 


\section{Resumen}

Este estudio examina los mensajes intercambiados en foros de discusión virtuales que se centran en el uso de hormonas trans, es decir hormonização, un término acuñado para diferenciarlos de la terapia hormonal, administrado por profesionales de la salud. Se encuestó a tres comunidades alojadas en la red social Orkut, lo que representa un total de 370 tablas, y se analizaron los usos de las hormonas y los informes de los desacuerdos entre los usuarios y los profesionales de la salud. Observe que si por un lado el hormonização aumenta los efectos adversos de las intervenciones basadas en las dosis altas de los fármacos, por el otro, aparece como una resistencia con respecto a los dispositivos de clínico- patologización.

Palabras clave: Modos de vivir; Comunidades trans; Hormonas

\section{O pulso ainda pulsa \\ E o corpo ainda é pouco \\ Ainda pulsa}

(Titãs)

\section{Introdução}

Este trabalho estuda mensagens trocadas em fóruns de discussões virtuais, alojados na rede social Orkut, voltados ao emprego trans de hormônios. Mais especificamente, busca argumentar que os medicamentos quando inseridos no cotidiano trana podem ser conceituados como fluxos que fazem parte da constituição de modos de viver que resistem a sua inclusão em dispositivos médicos-clínicos de patologização. Utilizamos a terminologia trans para referir aos modos de vida que passam por modificações nos corpos e transpõem fronteiras definidas por critérios heteronormativos.
As usuárias incluídas por nós na categoria trans se autonomeiam de diversas formas e algumas vezes, inclusive, transitam entre elas (crosdress, travestis, transexuais etc.). Construir ativamente margens de indeterminação é importante para produzir uma escrita despatologizante (Leite Júnior, 2012), pois as nomeações são sempre arriscadas por limitarem trânsitos e gerarem tipologias que agregam e homogeneízam.

A internet possibilitou a emergência de diversificados fóruns de discussões nas redes sociais, engendrando actantes e materialidades ${ }^{1}$. Neste estudo, os fóruns pesquisados se ordenam em torno da discussão sobre os múltiplos usos de hormônios (recreativos ou terapêuticos). Tais comunidades funcionam sem a mediação de profissionais especializados (Conrad, 2005, Vasconcellos-Silva \& Castiel, 2009), 
articulando "corpos hormonais"" que, seguindo discussões de Foucault (1979), podem ser considerados frutos de um emergente regime biopolítico ${ }^{3}$ que prioriza de forma específica determinados expertises, ou certas formas de produção de verdades (por exemplo: psiquiatria, psicologia, endocrinologia e sexologia), bem como modalidades de subjetivação que encontram nos fármacos um dos seus vetores mais importantes.

$\mathrm{Na}$ atuação crescente das indústrias farmacêuticas, somos capitalizados em fluxos globais, onde o medicamento passou a ser símbolo de comprovação de eficácia científica, integrando-se ao que Preciado (2008) nomeia "biocapitalismo farmacopornográfico", caracterizado pela produção de corpos como interfaces tecnorgânica reguladas por grandes corporações em fluxos mundializados de capital. Nesse quadro, os hormônios são um importante vetor de regime de governo dos corpos e das populações. Acabam mobilizados como mercadorias que, em sua dimensão pornográfica, agem na intensificação dos prazeres pela gestão de imagens de corpos desejáveis. Nesta "farmacopornografia" o consumo de hormônios não pode ser explicado apenas pelas benesses de suas propriedades químicas, já que seus efeitos agenciam $\operatorname{corpos}^{4} \mathrm{e}$ modos de nos relacionarmos conosco e com outros, mediante fluxos que vão de técnicas biomoleculares a imagens sensuais e pornográficas.

Apesar da existência de alguns poucos ambulatórios especializados em hormonoterapia trans $^{5}$ em cidades brasileiras e do significativo marco legal que garante o acesso à hormonoterapia na rede de saúde (Souza, 2009), a internet continua sendo um espaço privilegiado para a troca e composição do que se nomeia de "regimes hormonais", isto é, conjuntos de combinações e dosagens de fármacos que visam produzir novos contornos corporais e intensificar fluxos desejantes (Galindo, Moura \& Rodrigues, 2012).

Nas redes de comunicação virtual, a atuação do médico cede lugar a trocas informais e acesso mediado por expertises leigas. Ao invés da evidente expansão da medicina (Conrad \& Leiter, 2004), a internet tem nos colocado frente a um fenômeno paralelo: a erosão da Medicina como princípio de legitimação, ou fonte de informação para decisões quanto ao uso de fármacos ou adoção de modos de vida. Isso se torna visível, principalmente, quando há o uso de fármacos em prol do que não é considerado hegemonicamente saudável. Em outras palavras, os produtos químicos parecem não precisar tanto do médico ou da medicina para se tornarem legítimos. Além disso, os laboratórios investem em 
propagandas, destacando essa autonomia em relação ao saber médico.

\section{Fluências entre Saúde e Internet nas disjunções da Medicalização e} Farmacologização da vida

Medicalização é uma definição de contornos variáveis, utilizada principalmente até a década de 1980, aliada ao conceito de expropriação, como recurso para a crítica à diminuição da autonomia do usuário e ampliação do controle social da medicina a tal ponto que, como indica Menegon (2006), estende a abordagem médica a qualquer aspecto da vida.

Um amplo e nem sempre coerente conjunto de regulações busca concentrar as prescrições aos médicos, permitindo que os farmacêuticos façam apenas orientações aos que os procuram. No Brasil, as principais normas que legitimam a prescrição de medicamentos pelos médicos são a lei $\mathrm{n}^{\mathrm{o}} 5.991 / 73$, que dispõe sobre o controle sanitário do comércio de drogas, medicamentos, insumos farmacêuticos e correlatos, e dá outras providências; o decreto $\mathrm{n}^{\circ}$ 3.181/99, que regulamenta a lei $n^{\circ}$ 9.787/99, a qual estabelece o medicamento genérico, dispõe sobre a utilização de nomes genéricos em produtos farmacêuticos e dá outras providências; as resoluções da diretoria colegiada da Agência Nacional de Vigilância Rev. Polis e Psique, 2013; 3(2):19-42
Sanitária (Anvisa) no 80/2006, n $16 / 2007$ e $n^{\circ} 44 / 2010$, que dispõem sobre as práticas de funcionamento de farmácias; a portaria SVS/MS 344/98, que aprova o regulamento técnico sobre substâncias e medicamentos sujeitos a controle especial; e a resolução $n^{\circ} 357 / 2001$, do Conselho Federal de Farmácia, que aprova o regulamento técnico das Boas Práticas de Farmácia (Madruga \& Souza, 2009).

Na clínica do século XXI, o tempo de liberação de um medicamento para comercialização nem sempre segue os protocolos que atuariam na proteção do usuário. Destoam, portanto, dos "regimes de verdade" da biomedicina que se caracterizam pela comprovação experimental e controle dos efeitos adversos. A liberação pode seguir os chamados "regimes de esperança" que têm como critérios as pressões de grupos ativistas, sustentados no princípio de que se existe uma droga que pode ser eficaz, não se deveria esperar um tempo longo de comprovação científica (Moreira \& Palladino, 2005). Além do mais, a informação sobre os medicamentos se amplia e chega mais facilmente à população em geral em função do crescente interesse das empresas farmacêuticas e biotecnológicas em propagandas como forma de garantir o retorno de seus investimentos financeiros (Corand \& Leiter, 2004). Aliada a essa conjuntura, a internet se tornou espaço onde tecnologias 
biomédicas migram para o cotidiano e adquirem distintas características junto a usuários, médicos e propagandistas de medicamentos, como nos mostra Martin (2006) em uma pesquisa etnográfica realizada nos Estados Unidos.

Portanto, o termo medicalização e sua implicação na vida social estão se transformando. Trabalhos recentes começam a reavaliar o processo de medicalização, mostrando que embora o centro de sua definição continue com os médicos, ela agora pertence também ao âmbito do consumo (Conrad, 2005, 2007, Conrad \& Leiter, 2004, Clarke et. al., 2003). Outros trabalhos, muitos dos quais não são sociológicos, demonstram, ainda, que a medicalização agora é vista como disease-mongering, expressão utilizada para mostrar os esforços das campanhas farmacêuticas em criar ou exagerar uma doença com a finalidade de maximização dos lucros (Moynihan, 2002, Moynihan \& Henry, 2006, Moynihan, Heath \& Henry, 2002, Blech, 2006, Conrad \& Leiter, 2004).

Sob o impacto das transformações na área da saúde disparadas pelo consumo e atuação cada vez mais relevante das indústrias farmacêuticas, Conrad e Leiter (2004) argumentam que a medicalização se estende de tal maneira às relações entre empresas farmacêuticas, médicos e consumidores que preferem introduzir o termo "farmacologização" para captar a crescente preocu- pação do mercado farmacêutico em tratar e medicalizar doenças. Os autores destacam a influência que a propaganda exerce na medicalização, visando convencer o consumidor de que alguns produtos são os mais corretos, generalizando e potencializando-os para fins que vão muito além dos domínios da medicina ou da área da saúde de forma estrita. Dessa forma, instala-se um regime de maximização de resultados que garante a cada pessoa a supremacia na escolha do fármaco, tornando a consulta a um especialista (e, também, as indicações terapêuticas) um passo não obrigatório para produção de saúde ou bem-estar.

Maximizar resultados é, também, instalar-se num ideal de decência no qual cada um deve aparentar boa saúde, mesmo assolado pelos riscos persecutórios do adoecimento invisível (Vasconcellos-Silva \& Castiel, 2002, Moulin, 2008). Assim, de "pacientes" as pessoas passam ser consumidores ou consumidoras, o que coloca os fármacos no contexto dos demais bens de mercado. Ao pesquisarem comunidades virtuais sobre anorexia, Fox e Ward (2006) observam este mesmo deslocamento de "pacientes especialistas" (informados e exigentes quanto às medicações prescritas) a uma nova categoria denominada por eles como “consumidores resistentes" (que adquirem e alteram o emprego de medicamentos prescritos para outras finalidades). 
Na mesma direção, ao pesquisar sobre "doença dos nervos", Castro (2010) observou que mulheres medicadas no "posto de saúde" voltavam para suas comunidades e prescreviam os remédios "controlados" para vizinhas e amigas. De certo modo, poderíamos chamar essas mulheres de "consumidoras resistentes" já que elas passam a ser referência no grupo em relação à determinada "doença" (no caso citado, a doença de "nervos"). Uma vez "prescritos" por expertises leigas, os recursos para aquisição dos fármacos podem ser os mais variados. Em outra pesquisa, Loyola Filho et al (2002) citam alguns dos canais informais para aquisição: compra sem receituário, compartilhamento de medicamentos, utilização de sobras de prescrições, ou a reutilização de antigas receitas.

Dentro e fora da internet, alguns problemas, como os hormônios consumidos pelas trans, podem ser farmacologizados sem que necessariamente sejam medicalizados, pois nem sempre os setores médicos e farmacêuticos convergem. Uma tensão cotidiana entre farmacologização e medicalização é a advertência requerida das propagandas de fármacos: "em caso de efeito adverso o médico deve ser consultado". Nascimento (2005) chega a questionar se essa advertência, exigida pela Anvisa, seria mesmo uma regulação. É nesse sentido que, diante das transformações no consumo de fármacos e da reorganização da indústria farmacêutica, alguns trabalhos sobre a relação entre medicina e meios de comunicação se referem à "farmacologização" como processo decorrente da "medicalização" (Miah \& Rich, 2008, Fox, Ward \& O'Rourke, 2005a, 2005b) que tem suas próprias características. Os estudos assinalam que o uso de fármacos não se confunde com a ampliação da autoridade dos experts em medicina e ciências biomédicas.

Podemos afirmar que os usos de fármacos constantemente desbordaram a definição de tecnologias médicas ainda que incorporem, em sua materialidade, conhecimentos científicos e finalidades biomédicas que os tornaram possíveis (Fox \& Ward, 2006, Sabino, 2002). No Brasil, com a Resolução da Diretoria Colegiada (RDC) da Anvisa, $n^{\circ} 102$, publicada em Outubro de 2000, a internet passou a ser objeto de regulação quanto à propaganda de medicamentos, o que não diminuiu a margem deixada para trocas não institucionalizadas de fármacos.

O compartilhamento de informações sobre fármacos na internet - apesar de alertas sobre os riscos oferecidos - constituem-se, de certa forma, como resistências ao controle biomédico, ainda que não escapem aos dispositivos massivos de consumo estimulados pelas indústrias farmacêuticas, criando os "medicamentos dos sonhos", 
como acontece com o Perlutan (um hormônio com custo elevado) e outras tantas medicações que são introduzidas como soluções mais rápidas para efeitos esperados.

\section{Navegando nas comunidades do Orkut}

Quando iniciamos a pesquisa em 2009, existia no Orkut em torno de 40 comunidades direcionadas ao público trans, alguns deles voltados exclusivamente ao uso de medicamentos. Mesmo com o declínio do uso desta rede social, os fóruns continuam recebendo intensa movimentação do público trans, não migrando para outras redes sociais como, por exemplo, o Facebook. Assim, em 2011, o site de pesquisa sobre o meio digital ComScore lançou a pesquisa "The Brazilian Online Audience" que relata o modo como o mundo e os brasileiros estão utilizando a internet. Neste relatório é possível visualizar que o número de pessoas que faziam parte de comunidades online em 2009 era de 57\%; em 2010 este número cresceu para $60 \%$. A pesquisa mostra, ainda, que apesar do rápido crescimento de acesso ao Facebook pelos brasileiros $(258 \%$ de 2009 a 2010), o Orkut é, ainda, a rede social líder de acessos em algumas temáticas específicas. Enquanto no mundo o crescimento de acesso ao Orkut é de 1\%, no Brasil,-este número é de $28 \%$. Finalizando, os dados levantados apontam que $90 \%$ dos acessos ao
Orkut no mundo são realizados a partir de computadores brasileiros, e se não fossem esses acessos, esta rede social provavelmente teria deixado de existir em 2011 (Comscore, 2011).

Para localização das comunidades sobre hormônios, utilizamos a ferramenta de busca do próprio Orkut. Realizando o procedimento com a palavra "hormônio", identificamos seis páginas que correspondiam a comunidades sobre hormônios sem direcionamento aos usuários trans. A partir de uma segunda busca em que cruzamos "hormônios" e "trans", localizamos três comunidades que, para manutenção do sigilo, são aqui renomeadas como $\mathrm{C} 1, \mathrm{C} 2$ e C3 (procedemos da mesma forma com a identificação das usuárias, cujos nomes foram substituídos para preservação do sigilo).

$\mathrm{Na}$ sistematização inicial do material, confeccionamos um quadro composto por seis colunas, sendo elas: identificação com atribuição de um código a cada comunidade $(\mathrm{C} 1, \mathrm{C} 2, \mathrm{C} 3)$; número de usuárias; quantidade de fóruns postados; categoria de alocação da comunidade no Orkut; e, por fim, os objetivos explicitados. Em seguida, desenvolvemos um segundo quadro para cada comunidade, composto pelas seguintes colunas: fóruns, números de mensagens postadas, medicamentos mencionados, presença de receituário, dispositivos de segurança, procura de especialistas e observações. 
A primeira comunidade $\mathrm{C} 1$ foi fundada no dia 26 de outubro de 2004 e pertence à categoria "Saúde, Bem-estar e Fitnees". Quando realizamos os levantamentos dos fóruns, esta contava com 1.148 membros e seu conteúdo era privado, ou seja, apenas membros do Orkut vinculados à comunidade têm acesso ao que ali é postado. A comunidade C2 foi criada dia 5 de outubro de 2007, pertencente à categoria "outros", diferentemente da primeira comunidade, tinha seu conteúdo liberado para acesso de quem não é membro e, possuía 370 membros. A comunidade C3 contava com 981 membros, foi criada em 15 de abril de 2006, pertencia à categoria "Gays, Lésbicas e bi”, e assim como a C2, era aberta a não membros. Veja-se a Tabela 01 construída a partir das postagens nos fóruns:
$\mathrm{Na}$ análise, adotamos como recurso metodológico a seleção de "incidentes críticos" entendidos como "alguns eventos-chave que podem ilustrar aspectos que se deseja investigar, funcionando como possibilidades de microanálises que permitem entrever processos da construção de sentido sobre um dado fenômeno.” (Galindo, 2003, p. 30). Para seleção dos incidentes coletamos 186 fóruns de discussão da comunidade $\mathrm{C} 1,80$ da $\mathrm{C} 2$ e 41 da comunidade $\mathrm{C} 3$, totalizando 307 fóruns de discussão estudados. Esses fóruns possuíam, respectivamente, $2.115,2.301$ e 204 mensagens trocadas por usuários. Ressaltamos que as mensagens foram colhidas do dia 16 de abril de 2010 ao dia 27 de outubro de 2012. As mensagens selecionadas para compor o texto

Tabela 01 Caracterização dos fóruns sobre hormônios

\begin{tabular}{|c|c|c|c|c|}
\hline Comunidades & $\begin{array}{c}\mathrm{N}^{\mathrm{o}} \text { de } \\
\text { membros }\end{array}$ & $\begin{array}{l}N^{o} \text { de } \\
\text { fóruns }\end{array}$ & Objetivos & $\begin{array}{c}\text { Última data de } \\
\text { aceso }\end{array}$ \\
\hline $\mathrm{C} 1$ & 1148 & 555 & $\begin{array}{l}\text { Debater as consequências do uso dos } \\
\text { hormônios realizado por transexuais } \\
\text { e questões gerais relativas ao mundo } \\
\text { transexual e transgênero. }\end{array}$ & $\begin{array}{l}27 \text { de Outubro de } \\
2012\end{array}$ \\
\hline $\mathrm{C} 2$ & 370 & 125 & $\begin{array}{l}\text { Discutir modos (por meio da } \\
\text { ingestão de hormônios) de travestis } \\
\text { obterem o tão "almejado" corpo } \\
\text { feminino. }\end{array}$ & $\begin{array}{l}27 \text { de Outubro de } \\
2012\end{array}$ \\
\hline $\mathrm{C} 3$ & 981 & 319 & $\begin{array}{l}\text { Trocar ideias, opiniões e } \\
\text { experiências sobre o processo de } \\
\text { hormonização por transgênero na } \\
\text { busca de garantir o corpo (feminino) } \\
\text { desejado. }\end{array}$ & $\begin{array}{l}27 \text { de Outubro de } \\
2012\end{array}$ \\
\hline
\end{tabular}

Fonte: Elaboração própria com dados obtidos pela pesquisa 
foram escolhidas pelo critério de "presentatividade" e não a representatividade, tendo por critério de inclusão que o incidente faça parte da temática em estudo, tornando visíveis aspectos importantes a serem discutidos (Spink, 1999).

\section{Combinações e dosagens: "regimes}

\section{Hormonais"}

Os hormônios circulam na forma de cápsulas, soluções injetáveis, emplastros e gel. Com baixo custo, são facilmente adquiridos nas farmácias. Inclui-se aí o público trans que os utiliza para a produção de corpos que mesclam elementos numa complexidade que não se reduz ao binômio masculino/feminino, apesar de o reafirmarem vide a partição entre as comunidades com base nas transformações físicas almejadas: os fóruns que estudamos são restritos apenas à aquisição de atributos femininos, não sendo frequentados por homens trans. Há uma constante tensão entre a transposição de limites heteronormativos e reafirmação de binarismos que reafirmam dicotomias.

As trocas de informações sobre combinações e dosagens de hormônios são intensas. Usuárias neófitas, com pouca ou nenhuma experiência, acessam as comunidades para obterem informações sobre os "regimes hormonais", com usuárias mais experientes, trans que se "hormonizam" há bastante tempo. Ainda que informalmente as pessoas que utilizam os fóruns possuam diferentes estatutos e poder de fala, nem todas aconselham e, se o fazem, nem todos os conselhos são recebidos com o mesmo peso.

Ao longo dos fóruns, foram citados 19 hormônios. O Perlutan, fármaco com preço elevado, foi o mais citado, mostrando o nítido atravessamento do marketing que produz marcas e hierarquias de consumo e, para isso, os princípios ativos são omitidos, vindo ao primeiro plano os nomes comerciais. $\mathrm{Na}$ Tabela 02, elaborada na pesquisa, apresentamos os principais hormônios citados nos fóruns de discussão do Orkut e a respectiva frequência nas comunidades:

As dúvidas mais frequentes de usuárias neófitas são quanto à dosagem correta dos medicamentos e como combiná-los, ou seja, qual o conjunto de hormônios deve ser tomado para a aquisição de "atributos físicos femininos" (seios, nádegas, quadril, afinação de pêlos, redistribuição de gordura). Essas dúvidas são visíveis assim que acessamos as páginas de fóruns das comunidades, pois a maioria dos fóruns criados contém o nome do regime hormonal que se pretende consumir, como, por exemplo, o fórum intitulado: "Progesterona + cicloprimogina", disponível na comunidade C3. Regimes hormonais são combinações e dosagens de hormônios feitas por e para o público trans. Partindo de acepções dicio- 
Tabela 02 Principais hormônios citados nos fóruns de discussões

\begin{tabular}{|c|c|c|c|c|}
\hline Hormônios & C1 & $\mathrm{C2}$ & $\mathbf{C 3}$ & Total \\
\hline Perlutan & 186 & 32 & 20 & 238 \\
\hline Androcur & 179 & 16 & 12 & 207 \\
\hline Elamax & 125 & 12 & 4 & 141 \\
\hline Diane 35 & 79 & 13 & 5 & 97 \\
\hline Acetato de ciproterona (Androcur manipulado) & 87 & 2 & 3 & 93 \\
\hline Aldactone & 79 & 7 & 1 & 87 \\
\hline Finasterida & 81 & 4 & - & 85 \\
\hline Gestadinona & 65 & 4 & 2 & 71 \\
\hline Estrofem & 56 & 6 & 3 & 65 \\
\hline Cicloprimogyna & 50 & 9 & 4 & 63 \\
\hline Ciprostat & 46 & 5 & 5 & 56 \\
\hline Espironolactona & 46 & 3 & 3 & 52 \\
\hline Depo Provera & 32 & 7 & 3 & 42 \\
\hline Ciclo 21 & 15 & 11 & 3 & 29 \\
\hline Premarin & 16 & 9 & 2 & 27 \\
\hline Climene & 19 & 4 & 3 & 26 \\
\hline Andelux & 13 & 4 & 5 & 22 \\
\hline Acetato de medroxiprogesterona (progesterona) & 9 & 4 & 1 & 14 \\
\hline Repopil & 7 & 2 & 1 & 10 \\
\hline
\end{tabular}

Fonte: Elaboração própria com dados obtidos pela pesquisa

narizadas (Houaiss, 2004), para efeito deste texto, "combinar" equivale a consumir dois ou mais tipos distintos de hormônios, e "dosar" equivale ao estabelecimento da quantidade de substâncias a serem ingeridas.

Nas comunidades trans, os regimes hormonais se diferenciam das prescrições contidas nos protocolos dirigidos a esta população, com nítido incremento de doses e combinações entre os fármacos. No que concerne à combinação dos hormônios, usuárias experientes relatam que um bom Rev. Polis e Psique, 2013; 3(2):19-42 regime hormonal é aquele que vincula um fármaco que tem na sua composição antiandrógeno (composto químico responsável pela inibição da ação do androgênio-hormônio que mantém as características sexuais secundárias do homem), com hormônios considerados "femininos", como a progesterona. Eis a recomendação feita por Alice, usuária da comunidade C2: Alice: “[...] você podia tomar 1 perlutan a cada 15 dias e 1 diane ou Elamax por dia. Mas, basicamente seu regime hormonal está ok, afinal 
você toma o antiandrógeno, uma boa fonte de estrógeno e progesterona como a perlu$\tan [\ldots . .$. ." (Comunidade C2).

Em uma pesquisa com doze travestis canadenses que se hormonizam, Wassersug et al (2007) mostram que os regimes hormonais são utilizados de forma similar ao público trans do Orkut, carregando em sua composição combinações entre antiandrógeno receptor (spironolactone ou acetato de cyproterone) e estrógeno (estrógenos conjugados e/ou estradiol de ethinyl e/ou estriol). No Brasil, conforme Athayde (2001), a mesma composição é prescrita na rede de saúde pública para pessoas classificadas como transexuais: um antiandrogênio, que diminuirá as características masculinas e um estrogênio para viabilizar a construção de caracteres femininos secundários.

Passando às dosagens, estas são manipuladas com maior rigor do que as combinações entre fármacos, sendo frequentes alertas quanto ao uso excessivo. Usuárias experientes advertem que a ingestão excessiva de doses recomendadas de certo fármaco não acelera os efeitos dos hormônios, causando danos à saúde. Como precaução, várias usuárias também recomendam que um especialista seja procurado. Vejamos o relato de uma participante da comunidade C3:

Laura: Elamax e Perlutan juntos não devem fazer mal, se tomados em doses adequadas. O Perlutan, no máximo a cada 15 dias.
Eu já acho muito e recomendaria a cada 3 semanas ou um mês. E o Elamax em doses diárias de 2 a 4 comprimidos, dependendo do efeito que você quiser. Pois o Elamax tem as drágeas brancas que são puras valerato de estradiol (2mg) e as rosadas, que além do estradiol possuem acetato de ciproterona (1mg) (Comunidade C3).

As advertências sobre o chamado uso abusivo dos medicamentos aparecem desde a apresentação das comunidades. $\mathrm{Na} \mathrm{C} 2$, ao acessarmos a comunidade, visualizamos a seguinte advertência: "Esta comunidade foi criada para pessoas como eu, como você que almeja um corpo lindo, é claro com muito cuidado, através dos maravilhosos hormônios femininos." Já na C3, observamos um longo texto na página inicial, que destaca em caixa alta a recomendação de auxílio médico:

Comunidade destinada para trocarmosideias, opiniões e experiências sobre o processo de hormonização para pessoas transgênero na busca de adquirir o corpo desejado. Nossos comentários não têm o caráter de receita, nem substituem a consulta ao médico. Por outro lado, estamos atent@s às situações da vida real e nos baseamos em uma política de redução de danos, procurando orientar as pessoas contra os problemas e efeitos colaterais causados pelo uso excessivo de certos medicamentos. ATENÇÃO: RECOMENDAMOS O AUXÍLIO DE UM MÉDICO ENDOCRINOLOGISTA E DE UM PSICÓlOGO PARA ACONSELHAMENTOS, ANTES DE 
QUALQUER COISA!!! Confira, por meio do link a seguir, o Estatuto Código de Ética da Comunidade: [site da comunidade]. Ao admitir alguém na Comunidade, partimos do pressuposto que o interessado leu e concorda na íntegra com as determinações de nosso Estatuto (Comunidade C3).

Usuárias experientes indicam dosagens, levando em consideração o conjunto de hormônios indicado para aquisição de atributos físicos ditos femininos (seios, nádegas, quadril, afinação de pelos, redistribuição de gordura) sem danos à saúde. Elas calculam custos-benefícios uma vez que várias são adolescentes e ainda dependentes financeiramente de seus tutores, o que dificulta o acesso aos medicamentos mais caros, ou ainda incorporam conhecimentos que adquiriram em fóruns especializados:

Laura: Eu conheço uma transexual, por sinal bastante experiente, que toma uma injeção de Perlutan por semana e nunca passou mal. Porém, o fato de alguém fazer isso e não ter passado mal, também não significa que está fazendo bem, pois o nosso organismo tem um limite para absorver os hormônios. Mesmo que elas não tenham sentido nenhum efeito negativo (até agora), provavelmente tenham jogado dinheiro fora com tantas doses, pois o efeito feminizante de tomar uma dose a cada 7 ou 10 dias, ou a cada 21 ou 30 dias é praticamente o mesmo. Nosso organismo não absorve essas dosagens e elimina os excessos (Comunidade C3).
Ainda para escolher a dosagem dos hormônios é levada em conta a velocidade desejada para obtenção das transformações corporais, classificando os medicamentos em "fortes" e "fracos":

O melhor antiandrógeno é o Ciprostat (Androcur, igual, mas mais caro)... mas como você não quer algo muito forte, sugiro que divida cada comprimido em quatro e vá tomando cada $1 / 4$ de comprimido por dia... Ele vai suprimir a testo, mas não tanto assim, mas fique alerta, que a libido vai diminuir sim, pelo menos no começo. Outra sugestão que sei que algumas meninas usam é o perlutan, pois ele suprime levemente a testo, ou mesmo o depo-provera. (Comunidade $\mathrm{C} 2$ ).

De maneira similar ao que ocorre nos fóruns do Orkut, Conrad (1985), a partir de entrevistas com portadores de epilepsia, observa que além do "descumprimento de prescrições", os usuários colocam em funcionamento autorregulações: reduzem ou prolongam as doses diárias; ingerem doses extras em circunstâncias específicas e, por fim, param de ingerir as drogas por determinados períodos, ou definitivamente. $\mathrm{Na}$ mesma direção, Mol (1999), na Inglaterra, observa que os usuários de dispositivos de mensuração sanguínea para controle de níveis de glicose também desenvolvem princípios de autorregulação, utilizando além das prescrições horárias indicadas pelos médicos, as suas sensações corporais. 
Entre as dosagens e combinações, as usuárias trocam também experiências do cotidiano, de maneira que, no decorrer das trocas de mensagens, as perguntas e respostas sobre hormônios se mesclam a conversas, risos e lágrimas, em torno de relacionamentos amorosos. Isso levou uma das comunidades a criar um fórum apenas para "assuntos não relacionados a hormônios", cuja descrição é apresentada como "Tópico para bate-papo, conversas descontraídas e informais sobre nosso universo, fazer amizade, brincar e jogar conversa fora. Fiquem à vontade e aproveitem!!!" (Comunidade C3).

Os hormônios atuam num sistema de gênero/sexos/prazeres em constante deslocamento, sendo definidos e redefinidos ao longo do processo hormonização. Assim, como argumenta Preciado (2008), o gênero parece ser sintético, maleável, variável e suscetível de ser transferido, imitado, produzido e reproduzido tecnicamente "independente do órgão sexual", como relata uma usuária da Comunidade C3:

Débora: Eu já havia postado em outro tópico que me sinto me vejo como uma mulher, e não é meu órgão sexual que vai me definir se sou menos mulher, ou mais mulher!!! $\mathrm{Eu}$, por exemplo, não me importo ainda em ter um Pênis, nasci assim, me aceito assim, sou feliz assim, sabe? Mais eu não uso ele, nunca usei para ser ativa, não curto mesmo! Mais ali em cima você disse assim, Transex de verdade não gostam de ter o brinquedo, e os Travestis já não se importam de ter e usálos. Eu não me importo de tê-lo, mais não USO... Jamais... [...] EU sou o que eu penso ser, se me vejo mulher, me sinto mulher, é isso que eu SOU... Independente do meu órgão sexual!!! (Comunidade C3).

\section{Relatos de (des)encontros com profissionais de saúde}

Ainda que as comunidades atuem enquanto espaços para hormonização fora dos circuitos formais de administração, a busca de profissionais não é considerada dispensável pela maior parte das usuárias, convertendo-se em grandes circuitos de busca e desencontros. A procura por especialistas é sempre acompanhada de muito receio em função do preconceito dos profissionais da saúde diante das trans que subvertem a ideia do chamado "sexo biológico" como definidor do gênero que, por sua vez, orienta a indicação de determinados hormônios recomendados para "mulheres" ou "homens".

Apesar dos protocolos existentes dirigidos às trans, elas esbarram em dispositivos diagnósticos e patologizantes que podem ser expressos pela despretensiosa frase recorrente "não sei sobre o tema - ou sobre pessoas como você - e não posso atendê-la" ou, ainda, "o atendimento ao seu caso fere o código de ética médica": 
Alana: [...] como ouvi "não" de várias maneiras diferentes. [...] Estou com 21 anos, já era pra eu ter começado esse tratamento, mas eu simplesmente não acho um endócrino disposto a fazer [...]. Tudo que eles dizem é "não trabalhamos com este tipo de tratamento." Eu me inscrevi no tratamento do HC, pra conseguir endócrino via SUS, mas deve levar um ano pra fila andar. [...] eu tô a ponto de começar a hormonização por conta... Não quero esperar até ter 23 anos ou mais pra aí começar a me tratar. [...] Algumas de vocês fazem hormonização por conta? O que vocês podem me recomendar?

Amanda: Realmente não é nada fácil encontrar um bom endocrinologista que de fato compreenda a situação de uma pessoa disfórica. Mas eu acho que você tem várias opções:

1) Continuar procurando um médico [...], afinal por ser uma capital devem ter vários endocrinologistas e é altamente provável que você encontre o médico certo;

2) Falar com transexuais de São Paulo, Rio de Janeiro e outros estados, onde, com certeza, deve haver muitos endocrinologistas que fazem esse tratamento, e quando tiver um nome de algum médico, ligar para ele, marcar uma consulta e viajar até a cidade onde está o consultório (por mais longe que seja) e iniciar o seu tratamento;

3) Uma coisa que o endocrinologista não pode negar de maneira alguma é um exame para ver suas taxas hormonais atuais (níveis de eletrólitos, testosterona, progesterona, enfim), além de avaliar sua função hepática e renal, para ter certeza que está tudo bem com o seu organismo; 4) Há sempre a opção de INICIAR o tratamento por conta própria. Muitas, ou quase todas da comunidade fazem isso [...]. Seria uma opção para você ter certa tranquilidade enquanto continua sua busca, para agilizar o processo. Seria algo que eu faria (aliás, é o que estou fazendo).

Tenho 19 anos, e iniciei, depois de vários nãos de endócrinos o meu próprio tratamento, isso já faz uns 5 anos. E não me arrependo nem um pouco [...]. No começo, tive medo, mas hoje estou muito mais tranquila por saber que não estou produzindo testosterona em níveis masculinos (Comunidade $\mathrm{C} 1$ ).

Os relatos de fracasso na busca de tratamento especializado levam várias usuárias a desistirem de procurar orientação médica. Além disso, as orientações médicas recebidas nem sempre convergem com a larga tradição da hormonização trans que é, então, desconsiderada, fazendo com que, mais uma vez, as usuárias retornem às comunidades em busca de orientação. O que seria um atendimento clínico de rotina se torna uma "causa":

Samanta: Consegui conversar com um endócrino, embora ele não queira abraçar minha causa, ele me explicou bastante coisa, só tem uma coisa que ele disse que gostaria de saber sua opinião (referindo-se a opinião da usuária Amanda), pois experiência 
empírica é tudo (rs) e você tem muita. Ele disse pra, ao invés de tomar 1 ampola a cada 3 ou 4 semanas, seria melhor fracionar em 4 partes (1 ampola) e tomar 1 fração por semana. Desta forma, o organismo assimilaria melhor, o que você acha?

Amanda: Se a sua endocrinologista falou deve ter fundamento, mas eu pessoalmente não sei como se faz para fracionar uma ampola com apenas $1 \mathrm{ml}$ em quatro partes, afinal, depois que você abre a ampola e deixa muito tempo sem usar, em contato com o ar, imagino eu que o medicamento estrague. Ela te chegou a explicar como funcionaria esse fracionamento? E outra coisa, as mulheres genéticas $^{6}$ tomam o perlutan sem fracionar por uma simples razão, o medicamento embora injetado de uma só vez, vai sendo liberado aos pouquinhos no organismo, uma quantidade pequena a cada dia, então, é como se o seu organismo já "fracionasse" ele pra você. Afinal de contas, uma mulher que toma anticoncepcional em comprimidos está tomando um pouquinho de hormônio a cada dia, ao ingerir cada pílula diariamente, com o injetável é a mesma coisa, só que o organismo mesmo e a composição do remédio se encarregam disso. Mas é isto que eu sei, não sou médica, enfim, posso estar errada. Mas que bom que você procurou uma endocrinologista, mesmo que ela não tenha abraçado a sua causa, ela pode ajudar a checar as taxas hormonais e ver como está a sua saúde, já é alguma coisa. Bjs. (Comunidade $\mathrm{C} 2$ ).

Para a aquisição dos medicamentos, a farmácia é o único meio mencio- nado e quando esse assunto aparece normalmente refere-se a dúvidas de usuárias neófitas em relação às exigências para comercialização de fármacos que, em princípio, são destinados à população feminina. Mais uma vez, é o receio do constrangimento que atravessa os relatos e, para evitá-lo, são utilizadas estratégias como, por exemplo, anotar a relação de medicamentos que se deseja em papel (e assim não ter de falar alto o nome do medicamento), dizer que estão comprando para algum parente (tentando evitar questionamentos sobre o uso). Eis o trecho da postagem de Ângela que ilustra o receio de constrangimentos no momento da compra:

Ângela:Ésó pedir,não precisa dizernenhuma
senha secreta ou algo do gênero, basta levar
o nome do medicamento, esses que eu falei
acima anotado num pedaço de papel [...] e
dizer: "eu quero esse medicamento". [...].
Geralmente os farmacêuticos ou balconistas
não fazem muitas perguntas, qualquer coisa
é só você dizer que está comprando para um
parente, que o médico dele(a) indicou e você
está comprando para a pessoa. (Comunidade
C3). Diferentemente dos Estados Unidos (Bessel et al., 2003), o recurso à compra virtual não é mencionado nos fóruns pesquisados, cenário que parcialmente se justifica pelas relações entre usuárias e determinadas farmácias que passam a ser vistas como lo- 
cais seguros, sendo também recomendadas de uma a outra pessoa.

\section{Considerações finais}

O uso de fármacos nas comunidades trans escapam, parcialmente, aos diagramas biopolíticos de circulação que garantiam suas finalidades estratégicas enquanto dispositivos de controle. As formas de regulação, combinações e dosagens de hormônios se diferenciam dos convencionalmente vinculados aos protocolos dirigidos a esta população, já que são produzidas formas próprias de dosar, combinar e comprar que inventam circuitos de circulação, ao invés de apenas reproduzirem os existentes. E, principalmente, o uso trans de hormônios propõe modos de viver no quais se insinuam despatologizações urdidas em processos de farmacologização. Por despatologizações, denominamos os processos por meio dos quais o acesso a códigos tecnobionormativos de gênero não passa por diagnósticos nos quais a "autonomia" se confunde com "patologia", tal como nos protocolos de redesignação sexual que requerem o diagnóstico de disforia (Butler, 2009).

Dessa maneira, os usos trans de hormônios demandam que revisemos a definição destes como tecnologias de medicalização e patologização já que, como vimos argumentando, são reconfigurados em práticas de resistências. Esses usos (que não deixam de serem processos de farmacologização) são afirmações trans, uma prática de liberdade: na internet o público trans conta com toda uma tradição de produção de saberes e práticas sobre o uso de certos fármacos que vem se acumulando durante anos.

As trans (nomeação que não corresponde a nenhuma categoria específica ou modo de vida determinado, sendo, portanto, uma linha de fuga) problematizam práticas e normas disciplinares de um biopoder médico-clínico que patologiza os gêneros, articulando-se em rede sob a égide da AMIZADE. Elas resistem à medida que formam alianças, ou uma "trama afetiva" que traça linhas de força imprevistas, desestabilizadoras (Foucault, 1981). O combate às formas de opressão deve ser diário, contínuo, por isso menos utópico e mais heterotópico (Foucault, 1984), como fazem as trans. A partir das reflexões feitas aqui, constatamos que nas comunidades de discussões da internet são agenciados modos de vida pulsáteis, não porque neles identificamos unicamente sinais vitais reconhecíveis pela medicina (pulso diagnosticável no corpo), mas porque formam ritmos (cadências) resultantes das articulações entre os regimes hormonais e as modificações corporais que dizem respeito a modos de vida atravessados pelos fluxos desejantes não resumíveis aos corpos. 
O que concluímos, portanto, é que a renúncia das comunidades trans à busca de um saber formal médico não está ligada somente ao fato de profissionais da saúde ainda manterem este público sob o olhar desconfiado patologizante, mas também, de forma imbricada a esse fator, percebemos que a aliança afetiva que se desenvolve nas comunidades trans pesquisadas funciona como resistência positiva, já que esta relação que genericamente podemos nominar de AMIZADE funciona como condição estratégica para exercer o domínio sobre suas próprias vidas, configurando o que Foucault chamou (inspirado em Nietzsche) de "arte de existir".

Do ponto de vista das práticas psi, é importante que os profissionais e seus saberes tenham um exercício ativo que pirateie certa lógica inclusiva normalizadora (Galindo \& Méllo, 2010, Galindo \& Rodrigues, 2012, Méllo, 2012). Em decorrência desse posicionamento, não propomos transformar a internet em um ambulatório trans, em que os quais os fluxos sejam gerenciáveis. Entendemos como necessárias práticas que promovam saúde e reduzam danos associados à hormonoterapia nos espaços heterotópicos sem homogeneizações porque o corpo - mesmo pulsátil - “ainda é pouco". Assim, fazemos nossas as palavras de Foucault (1981, p. 5):

[...] a ideia de um programa e de proposições é perigosa. Desde que um programa se apresenta, ele faz lei, é uma proibição de inventar. Deveria haver uma inventividade própria de uma situação como a nossa e dessa vontade que os americanos chamam de comming out, isto é, de se manifestar. O programa deve ser vazio. É preciso cavar para mostrar como as coisas foram historicamente contingentes, por tal ou qual razão inteligíveis, mas não necessárias. É preciso fazer aparecer o inteligível sobre o fundo da vacuidade e negar uma necessidade; e pensar que o que existe está longe de preencher todos os espaços possíveis. Fazer um verdadeiro desafio inevitável da questão: o que se pode jogar e como inventar um jogo?

\section{Notas}

${ }^{1}$ Esses termos são afeitos da chamada "Teoria Ator-Rede". Actantes se refere a humanos e não-humanos que produzem uma ação, ou efeito, criando certo acontecimento. Já materialidades são os efeitos que tais actantes produzem quando se relacionam. As materialidades são sempre relacionais, não precedendo, ou sendo consecutivas às interações. (Law \& Mol, 1995).

2 Nos dois últimos séculos a noção de que possuímos um "corpo hormonal” passou a fazer parte não só do discurso médico, mas também do cotidiano das pessoas que por meio de artigos de jornais e revistas, programas televisivos e, recentemente, a internet entram em contato com a circulação de repertórios sobre hormônios como peças 
fundamentais para a construção e governo de si (Rhoden, 2008).

${ }^{3}$ Biopolitico é um conceito originalmente usado por Foucault para nos mostrar que o corpo, ou o que é conhecido como biológico, constitui-se em política que visa o gerenciamento do viver de uma população. Especialmente depois do século XVII, iniciase a instalação de um poder que não busca mais matar simplesmente, mas sim, investir na população por meio de intervenções e controles reguladores (Foucault, 1977). Um desses controles será a medicação.

4 " [...] um conjunto decididamente heterogêneo que engloba discursos, instituições, organizações arquitetônicas, decisões regulamentares, leis, medidas administrativas, enunciados científicos, proposições filosóficas, morais e filantrópicas. Em suma, o dito e o não-dito são os elementos do dispositivo. O dispositivo é a rede que se pode estabelecer entre estes elementos." (Foucault, 1979, p. 244).

${ }^{5}$ Em 9 de junho de 2009, surgiu, em São Paulo, o primeiro ambulatório do país especializado no atendimento de travestis e transexuais, a unidade foi acoplada ao Centro de Referência e Treinamento DST/Aids, com equipe de endocrinologistas, dermatologistas, urologistas, proctologistas, infectologistas, psicólogos e assistentes sociais.

6 "Mulheres genéticas" é uma expressão utilizada pelo público trans para designar Rev. Polis e Psique, 2013; 3(2):19-42 as pessoas que são consideradas "mulheres biologicamente", como se houvesse alguma predisposição de gênero. A esse respeito, ver discussões em Galindo \& Méllo (2010) e Méllo (2012).

\section{Referências}

Athayde, A. V. L. (2001). Transexualismo masculino. Arq Bras Endocrinol Metab, 45(4), 407-414.

Bessel, T. L., Anderson, J. N., Silagy, C. A., Sansom, L. N., \& Hiller, J. E. (2003). Surfing, self-medicating and safety: buying non-prescription and complementary medicines via the Internet. Qual. Saf. Health Care. 12, 88-92.

Blech, J. Inventing Diseases and Pushing Pills: Pharmaceutical Companies and the Medicalisation of Normal Life. London: Routledge, 2006.

Butler, J. (2009). Desdiagnosticando o Gênero. Physis, 19(1) 95-126.

Castro, C. A. de. (2010). Dando conta da "doença dos nervos": produção de sentidos em conversas com mulheres. 161f. Dissertação de Mestrado em Psicologia, Universidade Federal do Ceará, Fortaleza.

Clarke, S., Delamere, S., McCullough, L., Hopkins, S., Bergin, C., \& Mulcahy, F. (2003). Assessing limiting factors 
to the acceptance of antiretroviral therapy in a large cohort of injecting drug users. HIV Medicine, 4, 33-37.

Comscore. (2011). The Brazilian Online Audience. Global Leader in Measuring the Digital World. Recuperado em 05 de Setembro, 2012 de, http://www. comscore.com/por/.

Conrad,P.(1985). The meaning ofmedications: another look. At compliance. sot. sci. mrd., 20(1), 29-37.

Conrad, P. (2005). The Shifting Engines of Medicalization. Journal of Health and Social Behavior, 46, 3-14.

Conrad, P. (2007). The Medicalization of Society: On the Transformation of Human Conditions into Treatable Disorders. Baltimore: Johns Hopkins University Press.

Conrad, P., \& Leiter, V. (2004). Medicalization, Markets and Consumers. Journal of Health and Social Behavior, 45, 158-176.

Decreto $n^{\circ} 3.181$, de 23 de Setembro de 1999. (1999, 23 de Setembro). Regulamenta a Lei $n^{\circ} 9.787$, de 10 de fevereiro de 1999, que dispõe sobre a Vigilância Sanitária, estabelece o medicamento genérico, dispõe sobre a utilização de nomes genéricos em produtos farmacêuticos e dá outras providências. Brasília, DF: Presidência da República: Casa Civil.
Subchefia para Assuntos Jurídicos. Recuperado em 07 de Maio, 2013, de http://www2.camara.leg.br/legin/ fed/decret/1999/decreto-3181-23setembro-1999-345065-norma-pe. $\underline{\mathrm{html}}$.

Foucault, M. (1977). Discipline \& punish. Random House Digital.

Foucault, M. (1979). Microfisica do Poder. Rio de Janeiro: Graal.

Foucault, M. (1981, Abril). De l'amitié comme mode de vie. Entrevista de Michel Foucault a R. Ceccaty, J. Danet, \& J. Le Bitoux. Gai Pied, 25, 38-39. (Tradução de W. F. Nascimento). Recuperado em 24 de Setembro, 2012, de http://portalgens. com.br/portal/images/stories/pdf/ amizade.pdf.

Foucault, M. (1984). The History of Sexuality: An Introduction/Transl. from the French by Robert Hurley. Penguin Books.

Fox, N. J., Ward, K. J., \& O'Rourkea. (2005a). J. The 'expert patient': empowermen or medical dominance? The case of weight loss, pharmaceutical drugs and the Internet. Social Sciencce \& Medicine, 60, 1299-1309.

Fox, N. J., Ward, K. J., \& O’Rourkea. J. (2005b). Pro-Anorexia, Weight-loss drugs and the Internet: An 'Antirecovery' explanatory model f 
Anorexia. Sociology of Health and Illness, 27(2), 944-971.

Fox N. J., \& Ward, K. (2006). Health identities: from expert patient to resisting consumer. Health: An Interdisciplinary Journal for the Social Study of Health, Illness and Medicine, 10, 461-479.

Galindo, D. (2003). Dados Científicos como Argumento: o caso da redução de parceiros sexuais em Aids. Athenea Digital, 4, 26-41.

Galindo, D., \& Méllo, R. (2010). Piratarias de gênero: experimentos estéticos queer-copyleft. Psico, 41(1), 239245.

Galindo, D., Moura, M., \& Rodrigues, R. V. (2012). Uma dose queer: performances tecnofarmacológicas no uso informal de hormônios entre travestis. In: L. Souza, D. Galindo, \& V. Bertoline (Orgs.). Gênero, Corpo e@tivismo. Cuiabá: EdUFMT.

Galindo, D., \& Rodrigues, R. V. (2012). "Medicamentos copiados" nos fluxos transfronteiriços: consumo e clandestinidade. In: J. Chaves (org.). Psicologia e políticas públicas: contribuições e controvérsias. Goiás: Editora da PUCGoiás.

Houaiss, A. M. S. (2004). Dicionário Houaiss da língua portuguesa. Rio de janeiro: Objetiva.
Law, J., \& Mol, A. (1995). Notes on materiality and sociality. The Sociological Review, 43(2), 274294.

Lei $n^{\circ}$ 5.991, de 17 de Dezembro de 1973. (1973, 17 de Dezembro). Dispõe sobre o Controle Sanitário do Comércio de Drogas, Medicamentos, Insumos Farmacêuticos e Correlatos, e dá outras Providências. Brasília, DF: Presidente da República: Casa Civil. Subchefia para Assuntos Jurídicos. Recuperado em 07 de Maio, 2013, de http://www.planalto. gov.br/ccivil 03/leis/L5991.htm.

Lei $n .{ }^{\circ}$ 9.787, de 10 de Fevereiro de 1999. (1999, 10 de Fevereiro). Altera a Lei no 6.360, de 23 de setembro de 1976, que dispõe sobre a vigilância sanitária, estabelece o medicamento genérico, dispõe sobre a utilização de nomes genéricos em produtos farmacêuticos e dá outras providências. Brasília, DF: Presidente da República: Casa Civil. Subchefia para Assuntos Jurídicos. Recuperado em 07 de Maio, 2013, de http://www.mpba.mp.br/atuacao/ cidadania/gesau/legislacao/temas/ vigilancia/lei_9787 99.pdf.

Leite Júnior, J. (2012) Transitar para onde? Monstruosidade,(des)patologização, (in)segurança social e identidades 
transgêneras. Revista Estudos Feministas, 559-565.

Loyola Filho, A. I., Uchoa, E., Guerra, H. L., Firmo, J. O. A., \& LimaCosta, M. F. (2002). Prevalência e fatores associados à automedicação: resultados do projeto Bambuí. Rev. Saúde Pública, 36(1), 55-62.

Madruga, C. M. D., \& Souza, E. S. M. (2009). Manual de orientações Básicas para prescrição médica. João Pessoa: Idéia.

Martin, E. (2006). The Phamaceutical person. BioSocieties, 1, 273-287.

Méllo, R. P. (2012). Corpos, heteronormatividade e performances híbridas. Psicologia \& Sociedade, 24(1), 197-207.

Menegon, V. S. M.(2006). Entre a linguagem dos direitos e a linguagem dos riscos: os consentimentos informados na reprodução humana assistida. São Paulo: Editora PUCSP, EDUC (Série Hipótese).

Miah, A., \& Rich. E. (2008). The Medicalization of Cyberspace. Nova Iorque: Routledge.

Mol, A. (1999). Ontological politics: a word and some questions. In: J. Law, \& J. Hassard. Actor Network Theory and After. (pp. 74-89). Oxford: Blackwell.
Moreira, T., \& Palladino, P. (2005). Between truth and hope on Parkison's disease, neurotransplantation and the production of the "self". History of the Human Sciences, 18(3), 55-82.

Moulin, A. (2008). O corpo diante da Medicina. In: J. J. Cortine (Org.). História do Corpo. Mutações do olhar. Século XX. (pp. 15-82). Rio de Janeiro: Vozes.

Moynihan, R. (2002). Alosteron: A case study in regulatory capture or a victory for patients rights? $B M J$, 325, 592-595.

Moynihan, R., Heath, I., \& Henry, D. (2002). Selling sickness: The pharmaceutical industry and disease-mongering. BMJ, 324, 886-891.

Moynihan, R., \& Henry, D. (2006). The Fight against Disease Mongering: Generating Knowledge for Action. PLoS Med, 3(4), 191.

Nascimento, A. (2005). “Ao persistirem os sintomas, o médico deverá ser consultado”. Isso é regulação? São Paulo: Sociedade Brasileira de Vigilância de Medicamentos.

Portaria $n^{\circ}$ 344, de 12 de Maio de 1998. (1998, 12 de Maio). Aprova o Regulamento Técnico sobre substâncias e medicamentos sujeitos a controle especial. Brasília, DF: Agência de Vigilância Sanitária, 
Secretaria de Vigilância Sanitária do Ministério da Saúde. Recuperado em 07 de Maio, 2013, de http:// www.anvisa.gov.br/scriptsweb/ anvisalegis/visualizadocumento. asp $\mathrm{id}=939 \&$ versao $=2$.

Preciado, B. (2008). Testoyonqui. Madri: Esparsa.

Resolução RDC n $n^{\circ} 102$, de 30 de Novembro de 2000. (2000, 30 de Novembro). A Diretoria Colegiada da Agência Nacional de Vigilância Sanitária no uso da atribuição que the confere o art. 11 inciso IV do Regulamento da Agência Nacional de Vigilância Sanitária aprovado pelo Decreto n. ${ }^{\circ}$ 3.029 , de 16 de abril de 1999, c/c o artigo $8^{\circ}$, IV do Regimento Interno aprovado pela Portaria $n^{0} 593$ de 25 de Agosto de 2000, em reunião realizada em 29 de novembro de 2000. Brasília, DF: Agência Nacional de Vigilância Sanitária, Diretoria Colegiada da Anvisa. Recuperado em 07 de Maio, 2013, de http://www. fenapro.org.br/legislacao/download/ resol_102_00rdc.pdf

Resolução RDC $n^{\circ} 80$, de 11 de Maio de 2006. (2006, 11 de Maio). O DiretorPresidente Substituto da Agência Nacional de Vigilância Sanitária, no uso da atribuição que lhe confere o inciso IV do art 13 do Regulamento da ANVISA aprovado pelo Decreto $n^{\circ} 3.029$, de 16 de abril de 1999. Brasília, DF: Agência Nacional de Vigilância Sanitária, Diretoria Colegiada da Anvisa. Recuperado em 07 de Maio, 2013, de http:// www.anvisa.gov.br/hotsite/fraciona/ rdc 80.htm.

Resolução RDC $n^{\circ}$ 16, de 02 de Março de 2007. (2007, 02 de Março). Aprova o Regulamento Técnico para Medicamentos Genéricos, anexo I. Acompanha esse Regulamento o Anexo II, intitulado "Folha de rosto do processo de registro e pós-registro de medicamentos genéricos". Brasília, DF: Agência Nacional de Vigilância Sanitária, Diretoria Colegiada da Anvisa. Recuperado em 07 de Maio, 2013, de http://www.interfarma. org.br/site $2 /$ images/Site $\% 20$ Interfarma/Informacoesdosetor/RE/ Registro/2007/RDC\%2016-07.pdf. Resolução $n^{\circ} 357$ de 20 de Abril de 2001. (2001, 20 de Abril), Seção 1, p. 24 a 31. Aprova o regulamento técnico das Boas Práticas de Farmácia. Brasília, DF: Conselho Federal de Farmácia. Recuperado em 07 de Maio, 2013, de http://portal.crfsp.org. br/juridico/1169-resolucao-no-357de-20-de-abril-de-2001-cff.html. 
Resolução RDC $n^{\circ} 44$, de 26 de Outubro de 2010. (2010, 26 de Outubro). Dispõe sobre o controle de medicamentos à base de substâncias classificadas como antimicrobianos, de uso sob prescrição médica, isoladas ou em associação e dá outras providências. Brasília, DF: Agência Nacional de Vigilância Sanitária, Diretoria Colegiada da Anvisa. Recuperado em 07 de Maio, 2013, de http:// bvsms.saude.gov.br/bvs/saudelegis/ anvisa/2010/res0044_26_10_2010. $\underline{\mathrm{html}}$.

Rhoden, F. (2008). O império dos hormônios e a construção da diferença entre os sexos. História, Ciências, SaúdeManguinhos, 15, 133-152.

Sabino, C. (2002). Anabolizantes: drogas de Apolo. In: M. Goldenberg (Org.). $\mathrm{Nu}$ e vestido: dez antropólogos revelam a cultura do corpo carioca (pp.138-188). Rio de Janeiro: Editora Record.

Souza, E. J. (2009). Plano Nacional de Promoção da Cidadania e Direitos Humanos de Lésbicas, Gay, Bissexuais, Travestis e Transexuais. Brasília: Secretaria Especial dos Direitos Humanos.

Spink, P. (1999). Análise de documentos de domínio público. In: P. SPINK, P. Práticas discursivas e produção de sentidos no cotidiano (pp. 123-151).

São Paulo: Editora Cortez.

Vasconcellos-Silva, P. R, \& Castiel, L. D. (2002). Internet e o autocuidado em saúde: como juntar os trapinhos? Hist Cienc Saude Manguinhos, 9(2), 291-314.

Vasconcellos-Silva, P. R., \& Castiel, L. D. (2009). As novas tecnologias de autocuidado e os riscos do autodiagnóstico pela Internet. Rev. Panam Salud Publica/Pan Am J Public Health, 26(2), 172-175.

Wassersug, R., Gray, R. E., Barbara, A., Trosztmer, C., Raj, R., \& Sinding C. (2007). Experiences of Transwomen with Hormone Therapy. Sexualities, 10(1), 101-122.

Dolores Galindo:Professora do Departamento de Psicologia e do Programa de Pós-Graduação (mestrado) em Estudos de Cultura Contemporânea, Universidade Federal de Mato Grosso (UFMT), Cuiabá, Mato Grosso, Brasil.

E-mail: dolorescristinagomesgalindo@ gmail.com

Ricardo Pimentel Méllo: Professor Associado do Departamento de Psicologia da Universidade Federal do Ceará (UFC), Fortaleza, Ceará, Brasil.

E-mail: ricardo_pm@uol.com.br 
Renata Vilela: Graduada em Psicologia e Mestranda do Programa de Pós-Graduação em Estudos de Cultura Contemporânea da Universidade Federal de Mato Grosso, Mato Grosso, Brasil. Bolsista da Coordena- ção de Aperfeiçoamento do Ensino Superior - CAPES.

E-mail: renatinha.vilela@gmail.com

Recebido em: 01/09/2013 - Aceito em: 24/03/2014 